17(12):1552-1566.

3. Shelat P.R., Kumbar S.K. (2015). Analysis of out door patients' prescriptions according to World Health Organization (WHO) prescribing indicators among private hospitals in Western India. Journal of Clinical and Diagnostic Research, 9(3):1-4.

4. Fadare J., Oladele 0. , Oludare 0. et al. (2015). Drug prescribing pattern for under-fives in a paediatric clinic in South-Western Nigeria. Ethiopian Journal of Health Sciences, 25(1):73-78.

5. Bô̂ Y tế (2017). Quyết định số 4041/QĐ-BYTngày 07 tháng 9 năm 2017 về việc ban hành Đề án tăng cường kiểm soát kê đơn thuốc và bán thuốc kê đơn giai đoan 2017-2020, Hà Nội.

6. Bô Y Tế (2016). Quyết đinh số 772/QĐ-BYT về việc ban hanh tài liệu "Hướng dẫn thực hiện quản lý sử dụng kháng sinh trong bệnh viện", Hà Nội.

7. Goel R.K., Bhati Y., Dutt H.K., et al. (2013). Prescribing pattern of drugs in the outpatient department of a tertiary care teaching hospital in Ghaziabad, Uttar Pradesh. Journal of Applied Pharmaceutical Science, 3(4):48-51.

8. Bantie L. (2014). Assessment of prescribing practice pattern in governmental health centers of Bahir Dar Town, Ethiopia. World Journal of Pharmaceutical Sciences, 2(10):1184-1190.

\title{
TUÂN THỦ ĐIỀU TRI TIÊTT TRỪ' HELICOBACTER PYLORI VÀ CÁC YẾU TỐ LIÊN QUAN Ở BÊ̂NH NHÂN ĐIỀU TRI NGOẠI TRÚ TẠI BỆNH VIỆN QUẬN 2, TP. HCM
}

\section{TÓM TẮT}

Đặt vấn đê: H.pylori có liên quan đến loét tá tràng và da dày, có thể dẩn đến xuất huyết tiêu hóa, thủng da dày và ung thư da dày. Tại Việt Nam, tỷ lệ nhiếm H.pylori trên bệnh nhẩn loét dạ dày tá tràng tự 60 đến $80 \%$ tuy nhiên hiệu quả điều trị H.pylori giảm dần từ $90 \%$ trong thập kỷ 90 xuống còn $60-70 \%$ sau năm 2010. Tỷ lê này liên quan đến tình trang kháng thuốc kháng sinh do người bệnh không tuân thủ điều trị. Đối tượng và phương pháp: Thiết kế cắt dọc trên 249 bênh nhân điều trị tiệt trừ H.pylori lần đâu, trên 18 tuổi. Bểnh nhân có kết quả cân lâm sàng $(+)$ sẽ được mời vào nghiên cứu và thu thập các thông tin dân số - xã hôi và lâm sàng. Sau khi uống thuốc 2 tuần sẽ tái khám và được đánh giá tuân thủ điêu trị. Đánh giá tuân thủ điều tri bao gồm 2 khía canh: tuân thủ thuốc và tuân thủ khônng dùng rượu bia, thuốc lá. Kết quả: Tỷ lệ tuân thủ thuốc, tuân thủ không uống bia rượu - thuốc lá, tuân thủ chung lần lượt là $84,74 \%, 95,58 \%$ và $83,13 \%$. Có mối liên quan có ý nghĩa thống kê giữa tuân thủ điều tri và: giới tính nữ $(R R=1,16 ; p=0,011)$, đi khám với mục đích tầm soát $(R R=1,17 ; p=0,033)$, có các bênh kèm theo $(R R=1,17$ lần; $p=0,012)$, đước tư vấn ( $(R R=1,16$ lần; $p=0,016)$, không có tiên sứ hút thuốc lá $(R R=1,87 ; p<0,001)$ và uống rượu bia $(R R=2,27 ; p<$ 0,019). Kết luận: Tî lệ tuân thủ thấp cho thây cần cải thiên khâu tư vấn và giáo duc sức khỏe.

Tư khóa: Tuân thủ điểu trị, H.pylori, điều trị tiệt trừ, tư vấn

\section{SUMMARY \\ COMPLIANCE WITH HELICOBACTER PYLORI}

*Bệnh viện Quận 2, TP Hồ Chí Minh

**Trướng $Đ H$ Y khoa Pham Ngoc Thach

Chịu trách nhiệm chính: Trân Đức Sĩ

Email: sitd@pnt.edu.vn

Ngày nhận bài: 2/1/2021

Ngày phản biên khoa hoc: 1/2/2021

Ngày duyệt bài: $1 / 3 / 2021$

\section{Hoàng Hải*, Trần Đức Sĩ *}

\section{TREATMENT AND RELATED FACTORS IN OUT PATIENTS AT DISTRICT 2 HOSPITAL, HCMC}

Introduction: $H$. pylori has been proved to be related to duodenal and gastric ulcers, which can lead to gastrointestinal bleeding, perforation and gastric cancer. In Vietnam, the prevalence of $\mathrm{H}$. pylori infection in patients with peptic ulcer is from 60 to $80 \%$. However, the effect of $\mathrm{H}$. pylori treatment gradually decreased from $90 \%$ in the 1990 s to 60 $70 \%$ after 2010 . This rate is related to antibiotic resistance due to the non-compliance of patients. Subjects and method: We recruitedin our prospective, cross-sectional study 249 adults with $\mathrm{H}$. pyloriwho were undergoing an eradication treatment for the first-time. Patients with $\mathrm{HP}(+)$ will be invited in study and asked for socio-demographic and clinical information. After 2 weeks of medication, a follow-up visit has been made and the compliance would be assessed. Compliance assessment according to the WHO definition includes 2 criteria: drug compliance and non-alcohol and tobacco compliance. Results: Therates of drugs compliance, nonalcohol-tobacco compliance, and general compliance were respectively $84.74 \%$, $95.58 \%$ and $83.13 \%$. There was a statistically significant association between adherence to treatment and: female sex $(R R=1.16 ; p=0.011)$, detected bygeneral check ( $R R=1.17 ; p=0.033)$, having comorbidities ( $R R=1.17 ; p=0.012)$, be counseled ( $R R=1.16 ; p=0.016)$, no history of smoking $(R R=1.87 ; p<0.001)$ and no history of drinking $(R R=2.27 ; p<0.019)$. Conclusion: Low compliance indicates a need for improvement in health education and counseling.

Keywords: Treatment compliance, H.pylori, eradication treatment, counseling

\section{I. ĐĂTT VẤN ĐỀ}

Helicobacter pylori (H.pylori) là một loại xoắn khuẩn gram âm vi hiếu khí chủ yếu lây nhiễm vào niêm mạc dạ dày. Nguy cơ mắc viêm loét dạ 
dày-tá tràng (VLDDTT) ở người nhiễm H.pylori tăng gấp 3-10 lần so với người không nhiễm. Các nghiên cứu ngoài nước cho thây $70-95 \%$ loét tá tràng và $30-70 \%$ loét da dày có liên quan đến H.pylori[ ${ }^{[5]}$.Việc điều trị tiệt trừ H.pylori là một trong các biện pháp chủ yểu ngăn ngừa xuất huyết tiêu hóa, thủng dạ dày và ung thư dạ dày. Thực trạng hiện nay cho thấy hiệu quả điều trị H.pylori giảm dần theo thời gian tại Việt $\mathrm{Nam}^{[1]}$. Tỷ lệ này liên quan đến tình trạng kháng thuốc kháng sinh đang tăng lên chủ yếu do người bệnh không tuân thủ liêu lượng, thời gian uống thuốc. Việc không tuân thủ điều trị dẫn đến việc chữa trị trở nên khó khăn và mất nhiều thời gian hơn.

Tại Viêt Nam, các nghiên cứu thường can thiệp tư vấn cho bệnh nhân trước khi khảo sát, kêt quả sau đó cho thây tỷ lệ tuân thủ cao; đặc biệt kết quả của tác giả Đặng Ngọc Qúy Huệ (2016) cho thấy tỷ lệ tuân thủ đên $96,99 \%{ }^{[1]}$.Tỷ lệ tuân thủ cao hơn một số nghiên cứu tại nước ngoài của Lefebvre (2013) hay của O'Connor (2009) với tỷ lệ tuân thủ lần lượt là $95 \%$ và $80 \%[4],[6]$. Chúng tôi thực hiên nghiên cứu này nhằm xác định tỉ lệ tuân thủ điêu trị thật sự (không can thiệp trước) và các yếu tố liển quan.

\section{II. ĐỐI TƯƠNG VÀ PHƯƠNG PHÁP NGHIÊN CỨU \\ 2.1. Thiết kế nghiên cứu: Thiết kễ cắt dọc, tiến cứu}

2.2. Đối tượng nghiên cứu: Bệnh nhân nhiễm H.pylori trên 18 tuổi đến khám và điều trị lần đầu tại khoa Khám bênh - Bênh viên Quân 2, Tp. HCM. Bệnh nhân có chẩn đoán ung thư dạ dày hoặc xuất huyết tiêu hóa (thuộc nhóm đối tượng không được chỉ định điều trị tiệt trừ H.pylori theo khuyến nghị) sẽ bị loại ra khỏi nghiên cứu.

2.3. Phương pháp thu thập số liệu: Dữ liệu nghiên cứu được thu thập theo phương pháp thuân tiên. Người bênh đển khám tai Khoa khám bệnh được chẩn đoán xác định bằng xét nghiệm hơi thở hoặc làm Clotest và chỉ định điều trị đúng theo quy trình của bệnh viện. Sau 2 tuần, chúng tôi sẽ đánh giá số lượng bệnh nhân quay lại tái khám hay không (tuân thủ tái khám). Sau đó, nhóm nghiên cứu sẽ giới thiệu, mời bệnh nhân các bệnh nhân tái khám tham gia vào nghiên cứu. Bệnh nhân sẽ được giải thích về thông tin, mục tiêu của nghiên cứu và quyền lợi của mình khi tham gia nghiên cứu. Bệnh nhân sẽ được đánh giá về mức độ tuân thủ điều trị dùng thuốc, tuân thủ ngoài thuốc (không uống rượu bia, không hút thuốc trong thời gian điều trị).
Bảng hỏi cũng bao gồm các thông tin về đặc điểm dân số, xã hội, dịch tễ và đặc điểm lâm sàng. Chúng tôi không tác động đến các hoạt động khám chữa bệnh hoặc tư vấn của bác sĩ điêu trị. Việc tư vấn giáo dục sức khỏe thêm chỉ được thực hiện sau khi hoàn thành khảo sát.

2.4. Phương pháp xử lý và thống kê số liệu: Nhập số liệu bằng phần mềm Epidata 3.1 và phân tích bằng phần mềm Stata 13.1. Sử dụng phương pháp thống kê mô tả: tuần suất và tỉ lệ \% với các biến số định tính, trung bình và đô lệch chuẩn với biến số định lượng. Biến kết cuộc tuân thủ sẽ được mô tả bằng tần suất và ti lệ \%. Thông kế phân tích với các phép kiểm Chi bình phương, Fisher-exact test và t-test.

\section{KẾT QUẢ NGHIÊN CỨU}

Trong thời gian nghiên cứu có 44 bệnh nhân không tuân thủ tái khám, chiếm $15,02 \%$. Chúng tôi đã thu thập và phân tích dữ liệu của 249 bệnh nhân có quay lại tái khám. Các dữ liệu phân tích sau đây chỉ tính trên tổng số 249 người này.Độ tuổi trung bình trong nghiên cứu này là 40,57 (ĐLC: 13,71). Trong nghiên cứu chúng tôi ghi nhận bệnh nhân là nữ giới nhiều hơn nam giới, tỷ lệ lần lượt là $55,82 \%$ và $44,18 \%$.

Phần lớn bệnh nhân có trình độ học vấn là trung học phố thông $(32,13 \%)$, tiểu học chiếm $13,65 \%$, trung học cơ sở chiếm $28,92 \%$ và trung cấp, cao đẳng; đại học, sau đại học lần lượt là $10,84 \%$ và $14,46 \%$. Bên cạnh đó, người tham gia nghiên cứu hầu hết đang sinh sống tại thành phố Hồ Chí Minh (67,47\%).

Khi đếm sỗ thuốc còn lại, chúng tôi nhận thấy 229 bệnh nhân (chiếm tỉ lệ 91,97\%) uống đầy đủ thuốc và $4,42 \%$ bỏ từ 2 đến 3 viên. Trong tổng số 229 bệnh nhân không còn thuốc, chúng tôi ghi nhận 18 bệnh nhân không uống thuốc đúng hướng dẫn. Những bệnh nhân này quên cữ thuốc và uống bù vào thời gian khác. Do đó những bệnh nhân này được chúng tôi đánh giá là không tuân thủ điêu trị. Vì vậy, kết quả nghiên cứu cho thấy chỉ có 211 bệnh nhân tuân thủ việc uống thuốc, chiếm tỷ lệ $84,74 \%$. Đối với khuyển cáo không uống rượu bia và hút thuốc lá thì có 238 bệnh nhân tuân thủ, 11 bệnh nhân vẫn còn uống rượu bia, hút thuốc lá trong quá trình điều trị H.pylori, như vậy tỷ lệ tuân thủ điều trị ngoài thuốc là 95,58\%. Tỳ lệ tuân thủ chung (bệnh nhân tuân thủ tốt dùng thuốc và không uống rượu bia, hút thuốc là) là $83,13 \%$.

Nghiên cứu chúng tôi ghi nhận những nguyên nhân dẫn đến việc không uống thuốc của bệnh nhân điều trị ngoại trú H.pylori là: quên uống 
thuốc, xuất hiện các tác dụng phụ khi uống thuốc, không phù hợp giờ giấc sinh hoạt, hết triệu chứng nên không uống tiếp. Trong đó, nguyên nhân được ghi nhận nhiều nhất là quên uống thuốc chiếm $12,45 \%$, những nguyên nhân còn lại tỷ lệ lần lượt là $0,80 \%, 1,61 \%$ và $0,80 \%$.

Bềnh nhân nữ có tỷ lệ tuân thủ điều trị cao gấp 1,16 lần (KTC 95\%: 1,03 - 1,31) so với bệnh nhân là nam giới, với $p=0,011$. Về lâm sàng, nghiên cứu chúng tôi ghi nhận hầu như những bệnh nhân đến khám khi có triệu chứng xuất hiện $(84,34 \%)$, còn lại phát hiện bệnh qua khám tổng quát. Có $27,71 \%$ bệnh nhân có các bệnh khác kèm theo (đồng mắc). Bệnh nhân đi khám với mục đích tầm soát có tỷ lệ tuân thủ điều trị cao gấp 1,17 lần (KTC 95\%: 1,06 - 1,29, $\mathrm{p}=0,033$ ) so với bệnh nhân đi khám vì có triệu chứng Bệnh nhân có các bệnh kèm theo có tỷ lệ tuân thủ điều trị gấp 1,17 lần (KTC 95\%: 1,06 $1,29, \mathrm{p}=0,012$ ) so với bệnh nhân không có các bệnh kèm theo.
Có 29,72\% bệnh nhân trả lời là đã từng được bác sĩ tư vấn. Những bệnh nhân này có tỷ lệ tuẩn thủ điều trị gấp 1,16 lần (KTC 95\%: 1,05 - 1,28, $\mathrm{p}=0,016$ ) so với bênh nhân không dược tư vấn.

Về hành vi sức khỏe, bệnh nhân có tiền sử hút thuốc lá và uống rượu bia lần lượt chiếm $30,12 \%$ và $70,68 \%$. Bệnh nhân có hút thuốc lá có tỷ lệ không tuân thủ cao gấp 1,87 lần (KTC $95 \%$ : $1,29-2,73, \mathrm{p}<0,001$ ) và bệnh nhân có tiền sử uống rượu bia có tỳ lệ không tuânthủ điêu trị cao gấp 2,27 lần (KTC 95\%: 1,05 - 4,88, $\mathrm{p}=0,019$ ).

Không tìm thấy mối liên quan có ý nghĩa thống kê giữa tuân thủ điều trị với phác đồ điêu trị $(p>$ $0,05)$. Nghiên cứu còn ghi nhận các tác dụng phụ mà bênh nhân điều trị H.pylori trải qua là: nhức đâu, chóng mặt $(16,87 \%)$, buồn nôn, nôn $(14,86 \%)$, mệt mỏi, chán ăn $(16,06 \%)$ và đắng miệng $(16,87 \%)$. Các biến cố bất lợi liên quan đến điều trị $\mathrm{H}$. pylori hiên chưa cho thấy sự khác biệt có ý nghĩa thống kê trong mẫu nghiên cứu.

Bảng 1. Môi liên quan giữa tuân thủ điều trị với các đặc điểm lâm sàng

\begin{tabular}{|c|c|c|c|c|}
\hline & \multicolumn{2}{|c|}{ Tuân thủ điều trị } & \multirow[b]{2}{*}{ Giá trị p } & \multirow[b]{2}{*}{ RR (KTC 95\%) } \\
\hline & $\begin{array}{c}\text { Có } \\
\mathrm{n}=207(\%)\end{array}$ & $\begin{array}{c}\text { Không } \\
\mathrm{N}=42(\%)\end{array}$ & & \\
\hline \multicolumn{5}{|c|}{ Giới } \\
\hline Nũ̃ & $123(88,49)$ & $16(11,51)$ & \multirow{2}{*}{0,011} & $1,16(1,03-1,31)$ \\
\hline Nam & $84(76,36)$ & $26(23,64)$ & & 1 \\
\hline \multicolumn{5}{|c|}{ Lí do đi khám } \\
\hline Tầm soát & $37(94,87)$ & $2(5,13)$ & \multirow{2}{*}{ 0,033* } & $1,17(1,06-1,29)$ \\
\hline Có triệu chứng & $170(80,95)$ & $40(19,05)$ & & 1 \\
\hline \multicolumn{5}{|c|}{ Có các bệnh kèm theo } \\
\hline Có & $64(92,75)$ & $5(7,25)$ & \multirow{2}{*}{$0,012 *$} & $1,17(1,06-1,29)$ \\
\hline Không & $143(79,44)$ & $37(20,56)$ & & 1 \\
\hline \multicolumn{5}{|c|}{ Phác đồ } \\
\hline PPI + Bismuth + Metro + Tetra & $162(83,51)$ & $32(16,49)$ & & 1 \\
\hline PPI + Clari + Amox + Metro & $31(83,78)$ & $6(16,22)$ & $0,966 *$ & $1,01(0,86-1,17)$ \\
\hline 3 thuốc (PPI + Levo + Amox) & $14(77,78)$ & $4(22,22)$ & $0,585 *$ & $0,93(0,72$ \\
\hline \multicolumn{5}{|c|}{ Được bác sĩ tư vấn } \\
\hline Có & $68(91,89)$ & $6(8,11)$ & \multirow{2}{*}{$0,016 *$} & $1,16(1,05-1,28)$ \\
\hline Không & $139(79,43)$ & $36(20,57)$ & & 1 \\
\hline \multicolumn{5}{|c|}{ Có tiền sử hút thuốc } \\
\hline Không & $157(90,23)$ & $17(9,77)$ & \multirow{2}{*}{$<0,001$} & $1,87(1,29-2,73)$ \\
\hline Có & $50(66,67)$ & $25(33,33)$ & & 1 \\
\hline \multicolumn{5}{|c|}{ Có tiền sử dùng rượu bia } \\
\hline Không & $67(91,78)$ & $6(8,22)$ & \multirow{2}{*}{ 0,019* } & $2,27(1,05-4,88)$ \\
\hline Có & $140(79,55)$ & $36(20,45)$ & & 1 \\
\hline
\end{tabular}

*Fisher exact test

\section{BÀN LUẬN}

4.1. Tỉ lệ tuân thủ điều trị. Kết quả nghiên cứu của chúng tôi cho thây tỉ lệ tuân thủ điều trị tiệt trừ $\mathrm{H}$. pylori chung là $83,13 \%$, trong đó tuân thủ điêu trị thuốc là $84,74 \%$ và tuân thủ không sử dụng rượu bia, thuốc lá trong suốt thời gian điều trị ( 2 tuần) là $95,58 \%$. Kết quả của chúng tôi thấp hơn một nghiên cứu khác của Đặng Ngọc Quý Huê (2016) với 97,0\% bệnh nhân tuân thủ dùng thuốc tốt và $3,0 \%$ tuân thủ dùng thuốc 
kém khi được điều trị bằng phác đồ 4 thuốc có bismuth (EBMT) tại Bệnh viện đa khoa Thống Nhất, Đồng Nai ${ }^{[1]}$. Sự khác biệt có thể do chúng tôi chỉ ghi nhận hoạt động thực tế mà không can thiệp yêu câu các bác sĩ phải đặc biệt tư vấn cho bệnh nhân trong giai đoạn làm nghiển cứu.

So sánh với một số nghiên cứu trên thế giới kết quả chúng tôi không thấp hơn. Shakya Shrestha và cS (2016) cho thấy tỉ lệ tuân thủ điêu trị thuốc là $85,70 \%$, trong đó quển thuốc là lí do chính của không tuân thủ [7]. Lefebvre và cs (2013) cho thấy 64\% cho biết tuân thủ $100 \%$ thuốc và $80 \%$ cho biết tuân thủ $80 \%$ tổng thuốc và 29 người tham gia báo cáo tuân thủ kém (dưới $80 \%$ liều dùng $)^{[4]}$. Tỉ lệ tuân thủ này thấp hơn chúng tôi, lí do có thể là do đặc điểm dân số nghiên cứu. Lefebvre và cs (2013) cho rằng do nhóm đối tượng nghiên cứu là thổ dân Bắc Mĩ sinh sống tại Canada, nhóm dân số này có trình độ thông thạo tiếng Anh và học vấn khá thấp ${ }^{[4]}$.

Nghiên cứu chúng tôi ghi nhận những nguyên nhân lớn nhất dẫn đến việc không uống thuốc của bệnh nhân điều trị ngoại trú H.pylori là: quên uống thuốc $(12,45 \%)$. Nghiên cứu còn ghi nhận các tác dụng phụ mà bệnh nhân điều trị H.pylori trải qua. Các biến cố bất lợi liên quan đến điều trị $\mathrm{H}$. pylori rõ ràng là khác nhau giữa các phác đồ cũng có thể là một yếu tố ảnh hưởng đến sự tuân thủ. Nó đã được chứng minh rằng các tác dụng phụ có liên quan đáng kể đến thất bại điều trị và giảm tuân thủ ${ }^{[6]}$. Cần có thêm các nghiên cứu khác sâu hơn để trả lời câu hỏi này tại Việt Nam.O'Connor và cs (2009) ghi nhận không có trường hợp tử vong nào do tác dụng phụ của thuốc điều trị H.pylori được ghi nhận. Tuy nhiên, các tác dụng phụ phổ biến nhất bao gồm các triệu chứng khó chịu như: tiêu chảy, buồn nôn và nôn, các tác dụng phụ này có tác động đáng kể đến khía cạnh thể chất và sinh hoạt xã hội của bệnh nhân. Tác giả nhấn mạnh đến tầm quan trọng của việc tư vấn của bác sĩ và thông tin mà bệnh nhân nắm khi kết luận rằng bệnh nhân có nhiều khả năng chịu đựng các tác dụng phụ "nhỏ" hơn nếu họ hiểu rõ mục tiêu của điều trị cũng như phác đồ điều trị. Đối với các liệu pháp điều trị thay thế, bác sĩ sẽ phải quan tâm hơn đến các tác dụng phụ nặng hơn để tránh việc bênh nhân bỏ điều trị [6].

\subsection{Các yếu tố liên quan đến tuân thủ điêu trị}

- Giới tính: Trongnghiên cứu của chúng tôi nữ tuân thủ cao hơn nam giới, tương tự như nghiên cứu của Lê Thị Xuân Thảo (2016) tại bệnh viện Đại học $Y$ Dược thành phố Hồ Chí
Minh ${ }^{[2]}$. Tuy nhiên kết quả khác với những nghiên cứu trên thế giới. Shakya Shrestha và cS (2016) tại Nepal không nhận thây có mối liên quancó ý nghĩa thống kê giữa việc tuân thủ giới tính, tuổi tác, trình độ và chế độ điều trị được chỉ định của bệnh nhân ${ }^{[7]}$. Lefebvre và cs (2013) tại Canada nhận thấy sự tuân thủ $100 \%$ thuốc thường xuyên hơn ở nam giới (76\%) so vớinữ $(52 \%)^{[4]}$.

- Học vấn: Chúng tôi không tìm thấy mối liên quan có ý nghĩa thống kê giữa tuân thủ điều trị và học vấn. Kết quả nghiên cứu này tương đồng với một nghiên cứu của tác giả Lê Thị Xuân Thảo (2016) trên 330 bệnh nhân tại bệnh viện Đai học Y Dược thành phố HồChí Minh ${ }^{[2]}$.

- Nơi ở hiện tại: Chúng tôi không tìm thây mối liên quan có ý nghĩa thống kê giữa tuân thủ điều trị và nơi ở hiện tại. Những người bệnh sống tại quận 2 hoặc các tỉnh lân cận có tỉ lệ tuân thủ xấp xỉ nhau. Có thể thấy, người dân tại các vùng nông thôn đã có cải thiện ý thức bảo vệ sức khỏe và tuân thủ điều trị.

- Tuổi: Kết quả của chúng tôi tương đồng với Lê Thị Xuân Thảo (2016) trên 330 bệnh nhân tại bệnh viện Đại học Y Dược thành phố Hồ Chí Minh cho thấy những yếu tố liên quan với tuân thủ chung đúng là bệnh nhân thuộc nhóm 40 tuổi trở lênn ${ }^{[2]}$. Shakya Shrestha và cs (2016) tại Nepal không nhận thấy có mối liên quancó ý nghĩa thống kê giữa việc tuân thủ với tuổi tác ${ }^{[7]}$.

- Lí do đi khám: Chúng tôi tìm thấy bệnh nhân đi khám với mục đích tầm soát có tỳ lệ tuân thủ điều trị cao gấp 1,17 lần (KTC 95\%: $1,06-1,29$, với $p=0,033$ ) so với bệnh nhân đi khám vì có triệu chứng. Điều này có thể lý giải về mặt ý thức sức khỏe. Những người bênh chủ động đi tầm soát định kì ngay cả khi không có bất thường về sức khỏe phần nào cho thấy sự quan tâm của họ dành cho sức khỏe bản thân. Do đó, việc tuân thủ điều trị, đặc biệt là các bệnh lý có thể phát triển và diễn tiến phức tạp như H.pylori. Chúng tôi cũng không ghi nhận mối liên quan giữa thời gian có các triệu chứng và tuân thủ điều trị.

- Có bệnh kèm theo: Kết quả trong nghiên cứu của chúng tôi cho thây các bệnh nhân có các bệnh kèm theo có tỷ lê tuân thủ điều trị cao hơn so với bênh nhân khác. Đa phần bênh kèm theo được chúng tôi ghi nhận ở bệnh nhân điêuu trị tại Bệnh viện quận 2 là các bệnh mạn tính như: tăng huyểt áp, đái tháo đường và các bệnh lý về khớp. Có thể việc đã và đang dùng các thuốc điều trị hằng ngày có thể khiến cho bệnh nhân nhớ việc phải sử dụng thêm một thuốc 
điều trị ngắn ngày (điều trị $\mathrm{H}$. pylori là một trong số đó), từ đó tỉ lệ tuân thủ sẽ cao hơn nhóm không có bệnh kèm theo. Ngoài ra điêuu này cũng có thể liên quan đến nhận thức của họ về tình trang sức khỏe chung của bản thân.

- Phác đồ: Chúng tôi không tìm thấy mối liên quan có ý nghĩa thống kê giữa tuân thủ điều trị và phác đồ điều trị $(p>0,05)$. Kết quả này tương tự như các nghiên cứu trước đây. Misiewicz (1997) kết luận rằng mặc dù tác dụng phụ của các phác đồ 3 thuốc tiêu chuẩn là phổ biến, nhưng hiếm khi dẫn đến các tác dụng phụ nghiêm trọng buộc phải ngừng điều trị ${ }^{[5]}$.

- Bác sĩ tư vấn: Nghiên cứu chúng tôi tìm thấy bệnh nhân có được bác sĩ tư vấn có tỷ lệ tuân thủ điều trị cao hơn so với bệnh nhân không có tư vấn $(p=0,016)$. Lê Thị Xuân Thảo (2016) cho thấy tỉ lệ tuân thủ tăng lên đáng kể trước và sau khi bệnh nhân được tư vấn ${ }^{[2]}$. Một vài nghiên cứu cho thấy rằng bệnh nhân có biểu hiện tăng tuân thủ thuốc khoảng 5 ngày sau và trước khi đến gặp bác sĩ, hiện tượng này được gọi là "tuân thủ áo khoác trắng" và một thử nghiệm ngẫu nhiên có đối chứng đã chứng minh rằng việc tư vấn dùng thuốc và gọi điện nhắc nhở sau khi bắt đầu điều trị làm tăng khả năng tuân thủthuốclênđến $90 \%{ }^{[3]}$.

- Hút thuốc lá và uống rượu bia: Kết quả nghiên cứu cho thấy bệnh nhân không có tiền sử hút thuốc lá và dùng rượu bia có tỷ lệ tuân thủ hơn. Suzuki (2006) nhận thấy hút thuốc làm giảm hiệu quả tiệt trừ $H$. pylori do nhiều cơ chế: đâu tiên, hút thuốc làm giảm lưu lượng máu đến dạ dày, làm giảm tiết nhây và do đó làm giảm nồng độ kháng sinh tại niêm mạc dạ dày; kế đên, hút thuốc làm kích thích tăng tiết acid, có liên quan với điều trị thất bại do làm giảm tác dụng lên $\mathrm{H}$. pylori của amoxicillin, một kháng sinh dễ bị giảm sinh khả dụng trong mổi trường acid; hơn nữa, hút thuốc làm thay đổi hoạt động của isoenzymes cytochrome P450 liên quan đến chuyển hoá và giảm hoạt tính của PPI; và cuối cùng, hành vi hút thuốc trong quá trình điều trị cũng chứng tỏ bênh nhân tuân thủ điều trị kém ${ }^{[8]}$. Như vậy, có thể thấy đặc thù về tần suất sử dụng các chất kích thích như bia rượu, thuốc lá phụ thuộc rất nhiều vào các đăc điểm dân số xã hội. Do đó, các yếu tố này chồng chéo nhau và dẩn đến hế quả là hành vi sức khỏe kém, tiêu biểu là việc không tuân thủ điều trị.

\section{KẾT LUÂN}

Đánh giá sự tuân thủ điều trị thuốc sau 2 tuần điều trị cho thấy tỉ lệ tuân thủ điều trị của bệnh nhân tại BV Quận 2, tp HCM tương đối cao. Sự tư vấn của bác sĩ có thể nâng cao mức độ tuân thủ của bệnh nhân. Nguyên nhân chính của tuân thủ dùng thuốc kém là quên. Nên nhấn mạnh tầm quan trọng của việc tuân thủ và hướng dẫn bệnh nhân những biện pháp phòng tránh quên thuốc nếu cần thiết. Ngoài ra, cần đăc biệt lưu tâm tư vấn, khuyến cáo tuân thủ điều trị đối với những bệnh nhân nam giới có uống rượu, hút thuốc lá.

Nghiển cứu của chúng tôi chỉ giới hạn ở BV Quận 2, các bệnh viện có đặc điểm, đổi tượng bệnh nhân tương tự có thể tham khảo để có kế hoạch tư vấn nâng cao tỉ lệ tuân thủ điều trị tiệt trừ HP cho bệnh nhân. Tuy nhiên, cần có những nghiên cứu khác để có thể kiểm chứng và ứng dụng các kết quả này ở quy mô rộng hơn.

\section{TÀl LIỆU THAM KHẢO}

1. Đăng Ngoc Quý Huệ, Trân Văn Huy, Nguyễn Thanh Hải (2016) "Viêm dạ dày mạn do Helicobacter Pylori: Hiêu quả tiêt trừ của phác đồ bốn thuốc có BISMUTH' (EBMT)". Tạp chí Khoa học tiêu hóa Việt Nam 9, (45):149-158.

2. Lê Thị Xuân Thảo (2016) "Tuân thủ điều trị trong tiệt trừ Helicobater Pylori ở bệnh nhân viêm loét da dày tá tràng". Hội nghị KHKT Đại học Y Dược Thành phố Hồ Chí Minh lân thứ 34.

3. Abbasinazari, M., Sahraee, Z., Mirahmadi, $M$. (2013) "The Patients' Adherence and Adverse Drug Reactions (ADRs) which are Caused by Helicobacter pylori Eradication Regimens". Journal of clinical and diagnostic research : JCDR, 7, (3), pp. 462-466.

4. Lefebvre, M., Chang, H. J., Morse, A., van Zanten, S. V., Goodman, K. J. (2013) "Adherence and barriers to $\mathrm{H}$. pylori treatment in Arctic Canada". International journal of circumpolar health, 72, 22791-22791.

5. Misiewicz, J. J., Harris, A. W., Bardhan, K. D., Levi, S., O'Morain, C., Cooper, B. T., Kerr, G. D., Dixon, M. F., Langworthy, H., Piper, D. (1997) "One week triple therapy for Helicobacter pylori: a multicentre comparative study. Lansoprazole Helicobacter Study Group". Gut, 41, (6), 735-739.

6. O'Connor, J. A., Taneike, I., O'Morain, C. (2009) "Improving compliance with helicobacter pylori eradication therapy: when and how?". Therapeutic advances in gastroenterology, 2, (5), 273-279.

7. Shakya Shrestha, S., Bhandari, M., Thapa, S. R., Shrestha, R., Poudyal, R., Purbey, B., Gurung, R. B. (2016) "Medication Adherence Pattern and Factors affecting Adherence in Helicobacter Pylori Eradication Therapy". Kathmandu Univ Med J (KUMJ), 14, (53), 58-64

8. Suzuki, T., Matsuo, K., Ito, H., Sawaki, A., Hirose, K., Wakai, K., Sato, S., Nakamura, T., Yamao, K., Ueda, R., Tajima, K. (2006) "Smoking increases the treatment failure for Helicobacter pylori eradication". Am J Med, 119, (3), 217-224. 